\title{
Metallography as Decisive Source of Knowledge for Metallic Materials
}

\author{
Enrica Stagno \\ Section of Inorganic Chemistry and Metallurgy - Dept. of Chemistry and Industrial Chemistry, \\ University of Genoa (I)
}

Metallography is a technique that provides information about the microstructure of metals and alloys that are examined, through microscopical observation of suitably prepared specimens. Metallographic examination allows us to recognize important features, such as the nature, quantity, distribution, morphology and size of grains, phases or constituents. With this method we are also able to reveal the degree of homogeneity of solid solutions, the presence, amount, type, morphology and distribution of non-metallic inclusions and whether the material experienced deformation.

A combined analysis of the macroscopic and microscope observations produces a record of the specific thermo-mechanical history and also provides reasons for processing or service defects. Modern electron metallographic techniques do not present an alternative to macrographic and light microscopical examinations but provide an expansion of the general qualitative picture given by light optical microscopy by providing quantitative characterisation through targeted chemical and crystallographic analysis - powerful help in solving problems. But the specimen studied must be representative of the whole of the original material (from a compositional and a metallurgical point of view), if the information obtained is to be valid. The sample, properly prepared, is etched with the aim to underline and discriminate different structural elements. Several etching reagents might be used in this process. They should be classified in two categories. The first includes reagents that dissolve the products of their reaction with the metals. The second category includes reagents that form insoluble products with metals; these products remain in situ producing on the sample surface layers of different thickness. These films have different thickness from point to point and this can be estimated through interference colours.

Many years ago in our laboratory, a metallographic tinting technique was developed and utilized in numerous studies. This procedure was unique in that it combined dissolution etching (a reagent in the first category) followed by oxidation by heating in air at a suitable temperature and for a prescribed time that depended on the nature of the alloy. This produced an oxide film (a technique, heat tinting, in the second category) with a certain thickness that yielded a colour representing the chemical solid solution heterogeneity, the crystal orientation and the nature of hardening. In the 1960s, the electron microprobe and scanning electron microscope were new instruments and only a few research centres owned such instruments, this oxidation technique proved to be a very useful tool for revealing both primary heterogeneity, structural "heritage" phenomena (this information was not provided by the traditional metallographic techniques), crystalline orientation (texture) and deformation states [1-2]. With the method, it was possible to compare the entity of the phenomena, even though only qualitatively, by the colour after etching and to identify the presence of particular phases [3-6]. Some examples of the use of this method follow to illustrate its value.

By using the relationship between the primary structural heterogeneity, and its evolution through application of deformation and thermal treatments, it was possible to assess quite accurately the properties of the final product on the basis of the observed microstructural characteristics [7]. 
As an example, studies of tool steels using the tint-oxidation technique identified residual austenite (whose control is an important issue) present in small and scattered quantities. Further quantitative information was obtained more easily when the image analyser was used [8].

In order to reveal magnetic micro-fields, which appear on the surface of metallographic ferromagnetic specimens, a metallographic technique was implemented as an alternative to the method of Bitter. The Bitter technique employs colloidal solutions of ferrous oxides at high magnetic susceptibility. An electrolytic reagent containing molecular complexes with high magnetic susceptibility and an aggressive chemical action on the ferrite replaced the colloidal particles. In this way, the magnetic micro-fields were highlighted by selective corrosion. The magnetic figures in steel have a labyrinth shape and go through the ferrite grain boundaries without modifying themselves [9]. Examination of oxidised samples showed that the oxidation rate varied in the same way as the magnetic figure modifications. The resulting colour variation was able to reveal elasticplastic deformation up to the first stage while most sensitive instruments cannot reveal residual deformation after removal of the applied mechanical stress [10].

A study was conducted concerning the influence of different furnace atmospheres on the sintering of steel parts. Evaluation of phase ratios by microstructural observation of some components reported a carbon content lower than the nominal value supplied by $\mathrm{P} / \mathrm{M}$ manufacturer. Subsequent quantitative analytical information confirmed that decarburising occurred during their residence in the furnace. In additional, only the metallographic test could show superficial decarburising or carburising confined to a few $\mu \mathrm{m}$ of the surface by observing the nature, the relationship between phases and/or their distribution. Despite the importance of their application, those effects did not appear to influence amount of carbon measured [11].

Layers obtained by thermo-chemical treatments (i.e., nitriding, carburizing, nitrocarburising, etc.) on sintered components were also studied. The immediate information obtained by metallographic observations allowed us to evaluate the success rate of the treatments, even though the characterisation of the material was to be complemented by hardness measurements, EDS analysis, $\mathrm{X}$-ray diffractometry, mechanical tests and/or corrosion resistance and wear resistance tests [12].

\section{References}

[1] A. Scortecci, E. Stagno, Journèe Internationales de la Grosse Forge, Paris, Mai 1963

[2] A. Scortecci, E. Stagno, La Fonderia Italiana, XIV/11, 1965

[3] E. Stagno, M.R Pinasco, Mémories Scientifique de la Révue de Métallurgie, LXIV/9, 1967

[4] E. Stagno, M. G. Ienco, Alluminio, 3, 1971

[5] E. Stagno, M.G: Ienco, Sondersruck aus Radex-Raundshau, heft 3-4, 1972

[6] E. Stagno, M. R. Pinasco, Mémoires Scientifiques de la Révue Métallurgie, LXXIII, 2, 1976

[7] E. Stagno, Atti dell'Accademia Ligure di Scienze e Lettere, XXIV, 1967

[8] E. Stagno, M. R. Pinasco, Mémoires Scientifiques de la Révue Métallurgie, LXVI, 11, 1969

[9] E. Stagno, A. Scortecci, Mémoires Scientifiques de la Révue Métallurgie, LXII, 10, 1965

[10] A. Scortecci, E. Stagno, Mémoires Scientifiques de la Révue Métallurgie, LXII, 11, 1966

[11] E. Stagno, et al., La Metallurgia Italiana, EDIMET, XCII, 11/12, 2000

[12] E. Stagno, et al., Journal of Alloys and Compounds, 247, 1997

The author wishes to mention Professor Antonio Scortecci who introduced her in metallurgy field and supported her scientific growth. The author thanks the everlasting collaboration of her colleagues Prof. M.R. Pinasco and Prof. M. G. Ienco. Recently dott. P. Piccardo has been brought in her Metallurgy research Group. 